\title{
Field-Test of Electricity-Generating Tuned Mass Piezo-Damper on Real Bridge
}

\author{
E. S. Cho ${ }^{1 *}$, D. H. Ha ${ }^{2}$, J. F. Choo ${ }^{3}$, D. H. Lee ${ }^{4}$ and J. H. $\mathrm{Oh}^{5}$
}

\begin{abstract}
Keen attention is being paid worldwide on renewable energy. Apart from solar and wind power, piezoelectricity has recently attracted interest, especially when exploiting unused traffic energy. This paper presents the field-test results of the so-called Tuned Mass Piezo-Damper (TMPD) performed on a pedestrian bridge. TMPD is based on the well-known Tuned Mass Damper (TMD) used to control excessive structural vibrations but adds this device with energy-producing capability by introducing appropriately piezoelectric elements in the system. The electricity-generating capacity of the TMPD is evaluated by means of laboratory tests and a field-test conducted on a real pedestrian bridge in Seoul. The results show that the TMPD can provide sufficient electric power when tuned properly to the natural frequency of the controlled structure.
\end{abstract}

Index Terms-Electricity-generating capability, field-test, Tuned Mass Piezo-Damper (TMPD), unused traffic energy.

\section{INTRODUCTION}

Following the advances realized in design and construction technology, modern bridges are featured by slenderness and lightness that make them prone to vibration under all kinds of loads including traffic and wind. Such vibration problem becomes more acute in footbridges and has expressed recently through numerous complains introduced by pedestrians who felt uncomfortable and unsafe when crossing the footbridges. Authorities and engineers dealt with this problem by installing Tuned Mass Dampers (TMD) to control the excessive vibration of the bridges.

Besides, active research is being undertaken worldwide to exploit unused energy such as vibrational energy or traffic-induced energy. Among them, piezoelectric energy harvesting has received keen interest recently [1]-[3]. Especially, the authors developed the concept of Tuned Mass Piezo-Damper (TMPD) which, in addition to its original role of vibration controller, is a TMD enabling to harvest electric power from unused traffic energy by introducing piezocomposite elements in the device [4]-[5]. A previous paper [4] demonstrated the feasibility and soundness of the concept by means of laboratory experiments on a TMPD

\footnotetext{
${ }^{1 *}$ E. S. Cho is with the Civil Engineering Department of Konkuk University, Seoul, Korea

${ }^{2}$ D. H. Ha is with the Civil Engineering Department of Konkuk University, Seoul, Korea

${ }^{3}$ J. F. Choo is with the Energy Engineering Department of Konkuk University, Seoul, Korea

${ }^{4}$ D. H. Lee is with the Civil Engineering Department of Konkuk University, Seoul, Korea ${ }^{5}$ J. H. Oh is is with the Civil Engineering Department of Konkuk University, Seoul, Korea
}

prototype. The present paper developed a movable TMPD to examine its electricity-generating capacity through field-test on an actual pedestrian bridge in Seoul. The characteristics of this movable TMPD and the results of the field-test are presented.

\section{MOVABLE TMPD}

The conventional TMD is composed of a mass, springs and dampers that are designed to fit with the natural frequency of the structure to be controlled [6]. Since the dampers are the costliest elements in this system, the TMPD replaces them by a series of piezocomposite elements made of a flexible stainless plate on which a very thin piezoelectric ceramic layer is bonded [5]. Fig. 1 shows the TMPD where the piezocomposite elements are attached at the left and right ends of the mass. Laboratory tests demonstrated the feasibility and electricity-producing capacity of the TMPD shown in Fig. 1 [4]-[6]. The tests were conducted using a shaking table on which the TMPD was installed via a roller moving on a curved surface to transform the horizontal motion of the table into a vertical motion [7].

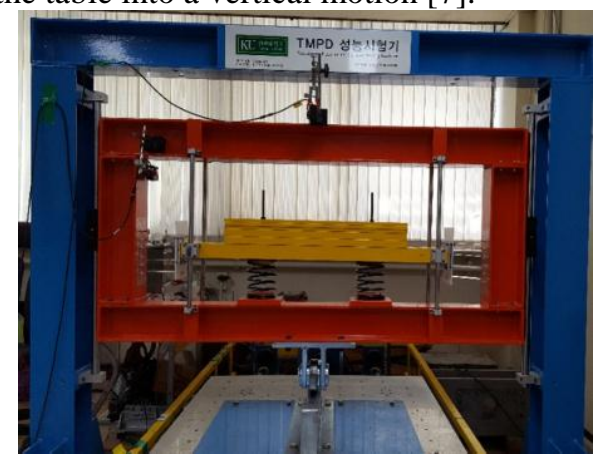

Fig. 1: Tuned Mass Piezo-Damper(TMPD).

For the field-test, a new TMPD was designed and fabricated as shown in Figs. 2 and 3. Since the TMPD could not be installed permanently on the footbridge, rollers were disposed at the base of the frame to ease its transportation on site. This new movable TMPD has the characteristics of that in Fig. 1 but was made more compact. With a mass of $95 \mathrm{~kg}$, the system was tuned to match the natural frequency of the footbridge presented in Chapter 3. Two sets of 8 piezocomposite elements were attached symmetrically at the edges of the mass. Each individual piezocomposite element presents stainless steel plate of $40 \times 120$ $\mathrm{mm}$ and piezoceramic of $38 \times 38 \mathrm{~mm}$ providing a natural frequency of $15.77 \mathrm{~Hz}$. The efficiency of the piezoceramic is 5 $\mathrm{mW} / \mathrm{cm} 2[4]-[5]$. 


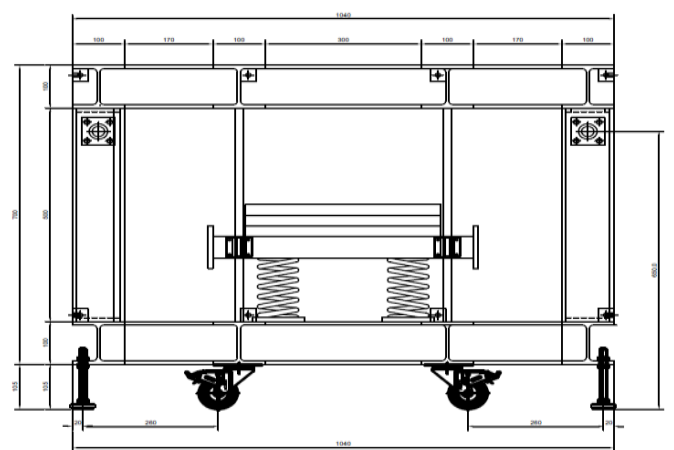

Fig. 2: Design drawing of movable TMPD

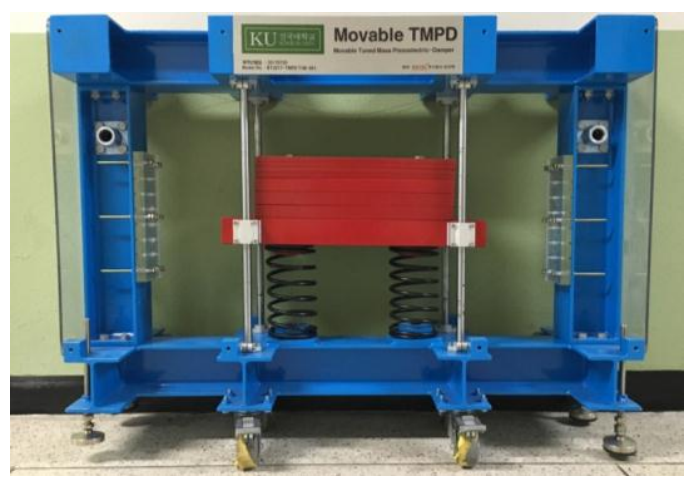

Fig. 3: Movable TMPD

\section{Characteristics Of Test FoOtbridge}

The bridge selected for the field-test is a typical pedestrian bridge with length of $45 \mathrm{~m}$ and width of $3.5 \mathrm{~m}$ that was recently completed in Seoul. The name and image of the bridge cannot be disclosed here due to the embargo of the managing authority.

The dynamic properties of the bridge were evaluated through free vibration test in which one person jumped at mid-span with a frequency of about $2 \mathrm{~Hz}$ during 20 seconds to simulate one pedestrian load. At the end of loading, all motions were stopped and the vertical acceleration of the bridge was measured using an accelerometer (AS-1 GB) during 1 minute to give the free vibration data shown in Fig. 4. The application of the logarithmic decrement method on the free vibration data provided a damping ratio of about $0.473 \%$, which falls far below the range of 2 to $3 \%$ generally exhibited in structures and showed that the selected footbridge is excessively underdamped and prone to vibration under pedestrian loading. Fig. 5 plots the results of the FFT analysis of the free vibration data in Fig. 4 and reveals that the natural frequency of the footbridge runs around $2.02 \mathrm{~Hz}$. This value corresponds to the natural frequency developed by most footbridges in Korea and indicates the potential risk of resonance to occur under pedestrian load. Consequently, the selected bridge necessitates additional damping in order to improve its serviceability and appears to be highly appropriate for the application of TMD in the form of the proposed TMPD.

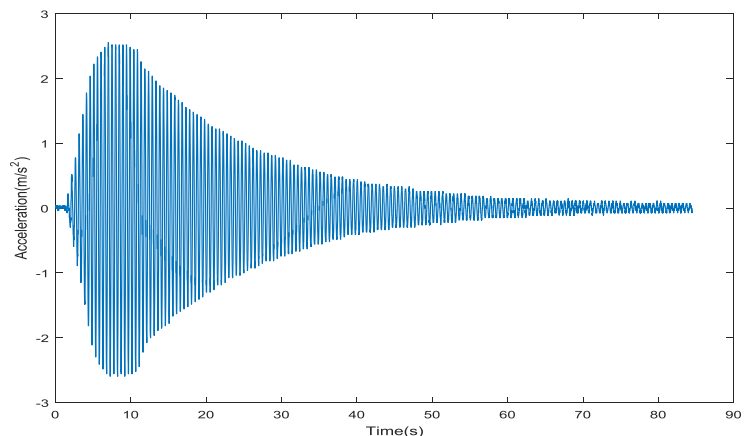

Fig. 4: Free vibration data of selected footbridge.

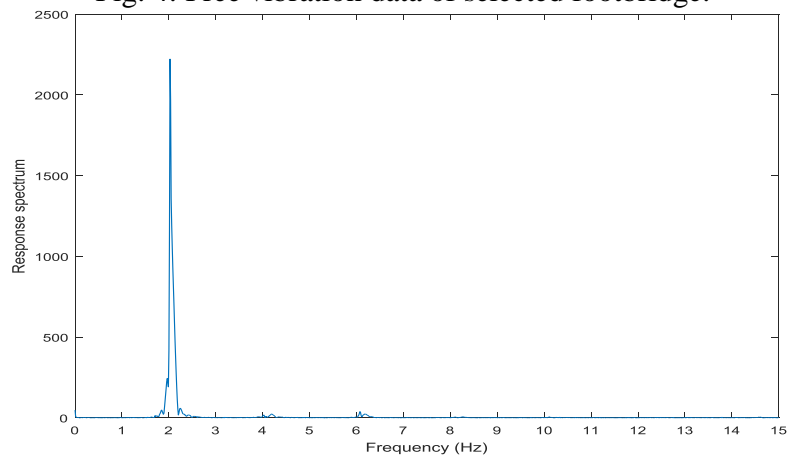

Fig. 5: FFT analysis results of Fig. 4.

\section{EVALUATION OF TMPD's ENERGY-PRODUCING CAPACITY BY FIELD-TEST}

Laboratory test applied a $2-\mathrm{Hz}$ vertical excitation on the TMPD and verified the adequate tuning of the system [7]. For the sake of comparability between the laboratory and field tests, both fixed and movable TMPDs were tuned to $2 \mathrm{~Hz}$.

For the field-test on the footbridge presented in the previous chapter, the movable TMPD was installed at mid-span and the vertical excitation was applied by jumping, walking and running on the bridge. The power-generating performance of the TMPD was measured by means of the voltage output through a matching resistance of $500 \mathrm{k} \Omega$.

Fig. 6 plots the vertical displacement of the TMPD's mass measured during 50 seconds in the laboratory and field tests. The comparison of the mass displacement data is done since this displacement is directly correlated to the deformation of the piezocomposite elements. In view of Fig. 6, the maximum vertical displacement of the mass reached $54.57 \mathrm{~mm}$ in the field-test and $44.44 \mathrm{~mm}$ in the laboratory test. The laboratory test results show more regular shape than those of the field-test because of the interference provoked by other pedestrians and the crossing of vehicles under the bridge during the field-test.

Fig. 7 plots the measured voltage output data corresponding to the 50-seconds mass displacement data of Fig. 6. It appears that the maximum voltage of the TMPD reached $123 \mathrm{~V}$ in the field-test and $152 \mathrm{~V}$ in the laboratory test. Such result was unexpected since larger displacement of the mass occurred in the field-test. However, a close observation of the graphs in Fig. 7 reveals that the voltage data of the field-test are slightly shifted upwards compared to those of the laboratory test. Accordingly, the comparison of the average voltage was conducted and confirmed our expectation since the field-test provided $46 \mathrm{~V}$ 
whereas the laboratory test gave an average voltage of $42 \mathrm{~V}$.
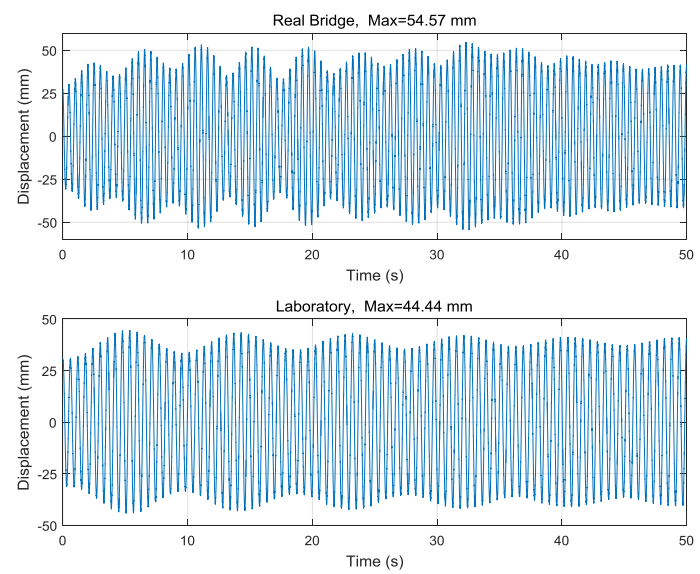

Fig. 6: Mass displacement data of TMPD's mass measured in field and laboratory tests
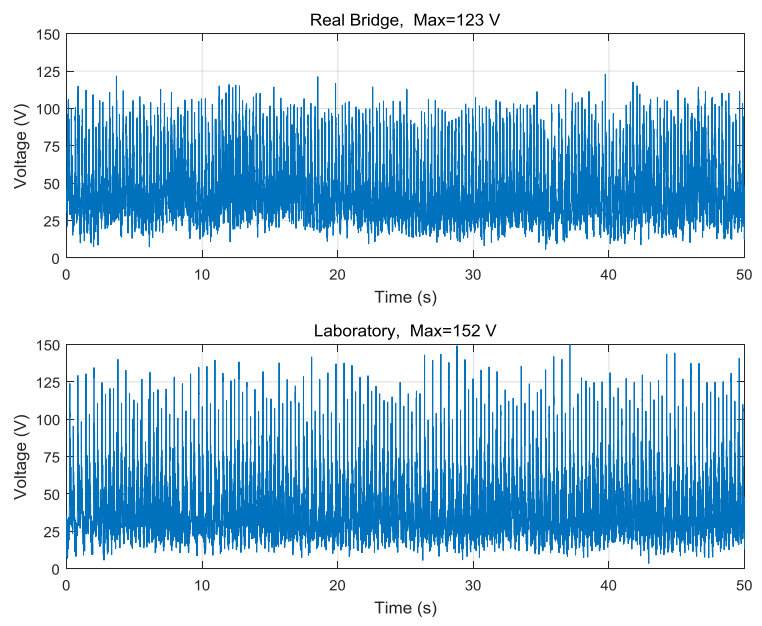

Fig. 7: Output voltage generated by TMPD in field and laboratory tests.

In order to drive more objective comparison, the electric power generated by the TMPD was computed. Equations (1) to (4) express the formulae used in the computation.

$$
\begin{array}{r}
V=I R \\
W=V I \\
1 \mathrm{Wh}=1 \mathrm{~W} \times 3,600 \mathrm{~s} \\
W=V^{2} / R
\end{array}
$$

Equation (1) is the classical Ohm's Law, which states that the current through a conductor between two points is directly proportional to the voltage across the two points. Equation (2) converts the voltage to electric power. Equation (4) is obtained by combining (1) and (2). Equation (4) is applied on all the data of Fig. 7 to derive the electric power generated by the TMPD converted to 1 hour of operation. The results show that the TMPD produced $31.72 \mathrm{kWh}$ in the laboratory test and 36.15 $\mathrm{kWh}$ the field-test. Table 1 arranges these values.
TABLE I: MaXimum Displacement, MaXimum Voltage, AND Power OF TMPD IN FIELD AND LABORATORY EXPERIMENTS

\begin{tabular}{|l|l|l|l|}
\hline & $\begin{array}{l}\text { Maximum } \\
\text { displacement }(\mathrm{mm})\end{array}$ & $\begin{array}{l}\text { Maximum } \\
\text { voltage }(\mathrm{V})\end{array}$ & $\begin{array}{l}\text { Power } \\
(\mathrm{kWh})\end{array}$ \\
\hline Field & 54.57 & 123 & 36.15 \\
\hline Laboratory & 44.44 & 152 & 31.72 \\
\hline
\end{tabular}

Considering some power loss for the storage of the electric power, we can assume that about $30 \mathrm{kWh}$ could be stored. Such amount of power is sufficient to feed approximately 100 LED lamps of $30 \mathrm{~W}$ during 1 hour. Consequently, the proposed TMPD in its current state proved to furnish enough energy for the nighttime lighting of the bridge.

\section{CONCLUSION}

TMPD is a TMD which, in addition to vibration controlling function, can harvest electric power from unused traffic energy by introducing piezocomposite elements in the device. The efficiency of this device has already been demonstrated through laboratory test. In this study, field-test on an actual footbridge was conducted to examine the electricity-generating of the TMPD under real conditions. To that goal, a movable TMPD was designed, fabricated and tuned to match the frequency of the footbridge. The field-test results indicated that the TMPD developed electricity-generating capacity comparable and even slightly superior to that observed in laboratory. This proved that the appropriate tuning of the TMPD to the natural frequency of the structure could induce resonance of the TMPD's mass and provide power-generating efficiency close to the predicted one. The use of one TMPD was seen to provide potentially enough electric power to feed the nighttime lighting of the footbridge. Further study will consider the use of multiple TMPDs and the type of connection (serial or parallel) enabling to generate larger amount of electric power from unused traffic energy.

\section{ACKNOWLEDGMENT}

This work is financially supported by Korea Ministry of Land, Infrastructure and Transport (MOLIT) as "Smart City Master and Doctor Course Grant Program".

\section{REFERENCES}

[1] R. Kour, and A. Charif. (March 2016). Piezoelectric roads: Energy harvesting method using piezoelectric technology. Innov. Ener. Res. [Online]. 5(1), doi: 10.4172/ier.1000132.

[2] J. F. Choo, V. L. Pham, and N. S. Goo, "Design of a $\mathrm{d}_{33}$-mode piezocomposite electricity generating element and its application to bridge monitoring," J. Cent. South Univ., vol. 21, pp. 2572-2578, 2014. https://doi.org/10.1007/s11771-014-2214-y

[3] K. V. Allamraju, and K. Srikanth, "State of art: Piezoelectric vibration energy harvesters," in Materials Today: Proc. 4, 2017, pp. 1091-1098.

[4] J. F. Choo, D. H. Ha, and H. K. Han, "Evaluation of energy-producing capability from pedestrian-induced vibration in footbridge by a new Tuned Mass Piezo-Damper," KSCE J. Civ. Eng., vol. 21, pp. 2322-2328, 2017.

https://doi.org/10.1007/s12205-016-2817-y

[5] D. Song, S. W. Min, J. H. Ahn, S. K. Hong, S. B. Kim, and T. H. Sung, "Study on improving current generating time of piezoelectric energy harvesting system," J. Electroceram., vol. 34(2-3), 2015, pp. 207-215. https://doi.org/10.1007/s10832-014-9974-5

[6] T. T. Soong, and M. C. Constantinou, "Principles of TMD and TLD Basic principles and design procedure," in Passive and Active Structural 
Vibration Control in Civil Engineering, Springer-Verlag, 1994, ch. IX, pp. 241-254.

[7] M. S. Seo, "Experimental Study on Tuned Mass Piezoelectric-Damper Using Shaking Table," Master dissertation, Dept. Civil. Eng., Konkuk Univ., Seoul, 2016.

[8] E. S. Cho, D. H. Ha, J. F. Choo, and D. H. Lee, "Test of movable TMPD on a real bridge," in Proc. 2017 Earthquake Engineering Society of Korea Conf., 2017, pp. 25-26.

[9] D. H. Lee, D. H. Ha, J. F. Choo, and E. S. Cho, "Verification for Damping and Power Generation Efficiency of Tuned-Mass-Piezoelectric-Damper," in Proc. 2017 Earthquake Engineering Society of Korea Conf., 2017, pp. 101-102.

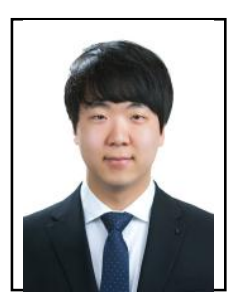

E. S. Cho is born in Suwon, Korea, in 1991 and enrolled in the Civil Engineering Department at Konkuk University in 2010. He obtained his BS in 2017 and enrolled the Graduate Program of the same department in 2017.

He fulfilled his military service from 2011 to 2013. From 2017 in the graduate school, he helped the faculty as Teaching Assistant in various classes including Structural Dynamics, Bridge Engineering \& Design, Statics and Structural Analysis. Meanwhile, he wrote several conference papers related to the topic discussed in this manuscript among them "Evaluation of Electric Power Generation Capacity of Tuned-Mass-Piezo-Damper" presented in KSCE 2017 Convention and "Test of movable TMPD on a real bridge" in EESK 2017 Conference. 